\title{
On the Convergence of an Implicit Iterative Process for Generalized Asymptotically Quasi-Nonexpansive Mappings
}

\author{
Xiaolong Qin, ${ }^{1}$ Shin Min Kang, ${ }^{2}$ and Ravi P. Agarwal ${ }^{3,4}$ \\ ${ }^{1}$ School of Mathematics and Information Sciences, North China University of Water Resources and \\ Electric Power, Zhengzhou 450011, China \\ 2 Department of Mathematics and the RINS, Gyeongsang National University, \\ Jinju 660-701, Republic of Korea \\ ${ }^{3}$ Department of Mathematical Sciences, Florida Institute of Technology, Melbourne, FL 32901, USA \\ ${ }^{4}$ Mathematics and Statistics Department, King Fahd University of Petroleum and Minerals, \\ Dhahran 31261, Saudi Arabia
}

Correspondence should be addressed to Ravi P. Agarwal, agarwal@fit.edu

Received 27 June 2010; Revised 16 October 2010; Accepted 10 November 2010

Academic Editor: Naseer Shahzad

Copyright (C 2010 Xiaolong Qin et al. This is an open access article distributed under the Creative Commons Attribution License, which permits unrestricted use, distribution, and reproduction in any medium, provided the original work is properly cited.

The purpose of this paper is to introduce and consider a general implicit iterative process which includes Schu's explicit iterative processes and Sun's implicit iterative processes as special cases for a finite family of generalized asymptotically quasi-nonexpansive mappings. Strong convergence of the purposed iterative process is obtained in the framework of real Banach spaces.

\section{Introduction and Preliminaries}

Let $E$ be a real Banach space and $U_{E}=\{x \in E:\|x\|=1\}$. E is said to be uniformly convex if for any $\epsilon \in(0,2]$ there exists $\delta>0$ such that for any $x, y \in U_{E}$,

$$
\|x-y\| \geq \epsilon \text { implies }\left\|\frac{x+y}{2}\right\| \leq 1-\delta .
$$

It is known that a uniformly convex Banach space is reflexive and strictly convex.

Let $C$ be a nonempty closed and convex subset of a Banach space $E$. Let $T: C \rightarrow C$ be a mapping. Denote by $F(T)$ the fixed point set of $T$. 
Recall that $T$ is said to be nonexpansive if

$$
\|T x-T y\| \leq\|x-y\|, \quad \forall x, y \in C .
$$

$T$ is said to be quasi-nonexpansive if $F(T) \neq \emptyset$ and

$$
\|T x-y\| \leq\|x-y\|, \quad \forall x \in C, y \in F(T) .
$$

A nonexpansive mapping with a nonempty fixed point set is quasi-nonexpansive; however, the inverse may be not true. See the following example [1].

Example 1.1. Let $E=R^{1}$ and define a mapping by $T: E \rightarrow E$ by

$$
T x= \begin{cases}\frac{x}{2} \sin \frac{1}{x} & \text { if } x \neq 0 \\ 0 & \text { if } x=0\end{cases}
$$

Then $T$ is quasi-nonexpansive but not nonexpansive.

$T$ is said to be asymptotically nonexpansive if there exists a positive sequence $\left\{k_{n}\right\} \subset$ $[1, \infty)$ with $k_{n} \rightarrow 1$ as $n \rightarrow \infty$ such that

$$
\left\|T^{n} x-T^{n} y\right\| \leq k_{n}\|x-y\|, \quad \forall x, y \in C, n \geq 1
$$

It is easy to see that every nonexpansive mapping is asymptotically nonexpansive with the asymptotical sequence $\{1\}$. The class of asymptotically nonexpansive mappings was introduced by Goebel and Kirk [2] in 1972. It is known that if $C$ is a nonempty bounded closed convex subset of a uniformly convex Banach space $E$, then every asymptotically nonexpansive mapping on $C$ has a fixed point. Further, the set $F(T)$ of fixed points of $T$ is closed and convex. Since 1972, a host of authors have studied weak and strong convergence problems of implicit iterative processes for such a class of mappings.

$T$ is said to be asymptotically quasi-nonexpansive if $F(T) \neq \emptyset$, and there exists a positive sequence $\left\{k_{n}\right\} \subset[1, \infty)$ with $k_{n} \rightarrow 1$ as $n \rightarrow \infty$ such that

$$
\left\|T^{n} x-y\right\| \leq k_{n}\|x-y\|, \quad \forall x \in C, y \in F(T), n \geq 1 .
$$

$T$ is said to be asymptotically nonexpansive in the intermediate sense if it is continuous and the following inequality holds:

$$
\limsup _{n \rightarrow \infty} \sup _{x, y \in C}\left(\left\|T^{n} x-T^{n} y\right\|-\|x-y\|\right) \leq 0 .
$$

Putting $\xi_{n}=\max \left\{0, \sup _{x, y \in C}\left(\left\|T^{n} x-T^{n} y\right\|-\|x-y\|\right)\right\}$, we see that $\xi_{n} \rightarrow 0$ as $n \rightarrow \infty$. Then (1.7) is reduced to the following:

$$
\left\|T^{n} x-T^{n} y\right\| \leq\|x-y\|+\xi_{n}, \quad \forall x, y \in C, n \geq 1 .
$$


The class of asymptotically nonexpansive mappings in the intermediate sense was introduced by Kirk [3] (see also Bruck et al. [4]) as a generalization of the class of asymptotically nonexpansive mappings. It is known that if $C$ is a nonempty closed convex and bounded subset of a real Hilbert space, then every asymptotically nonexpansive self-mapping in the intermediate sense has a fixed point; see [5] more details.

$T$ is said to be asymptotically quasi-nonexpansive in the intermediate sense if it is continuous, $F(T) \neq \emptyset$, and the following inequality holds:

$$
\limsup _{n \rightarrow \infty} \sup _{x \in C, y \in F(T)}\left(\left\|T^{n} x-y\right\|-\|x-y\|\right) \leq 0 .
$$

Putting $\xi_{n}=\max \left\{0, \sup _{x \in C, y \in F(T)}\left(\left\|T^{n} x-y\right\|-\|x-y\|\right)\right\}$, we see that $\xi_{n} \rightarrow 0$ as $n \rightarrow \infty$. Then (1.9) is reduced to the following:

$$
\left\|T^{n} x-y\right\| \leq\|x-y\|+\xi_{n}, \quad \forall x \in C, y \in F(T), n \geq 1
$$

$T$ is said to be generalized asymptotically nonexpansive if there exist two positive sequences $\left\{k_{n}\right\} \subset[1, \infty)$ with $k_{n} \rightarrow 1$ and $\left\{\xi_{n}\right\} \subset[0, \infty)$ with $\xi_{n} \rightarrow 0$ as $n \rightarrow \infty$ such that

$$
\left\|T^{n} x-T^{n} y\right\| \leq k_{n}\|x-y\|+\xi_{n}, \quad \forall x, y \in C, n \geq 1
$$

It is easy to see that the class of generalized asymptotically nonexpansive includes the class of asymptotically nonexpansive as a special case.

$T$ is said to be generalized asymptotically quasi-nonexpansive if $F(T) \neq \emptyset$, and there exist two positive sequences $\left\{k_{n}\right\} \subset[1, \infty)$ with $k_{n} \rightarrow 1$ and $\left\{\xi_{n}\right\} \subset[0, \infty)$ with $\xi_{n} \rightarrow 0$ as $n \rightarrow \infty$ such that

$$
\left\|T^{n} x-y\right\| \leq k_{n}\|x-y\|+\xi_{n}, \quad \forall x \in C, y \in F(T), n \geq 1
$$

The class of generalized asymptotically quasi-nonexpansive was considered by Shahzad and Zegeye [6]; see [6, 7] for more details.

Recall that the modified Mann iteration which was introduced by Schu [8] generates a sequence $\left\{x_{n}\right\}$ in the following manner:

$$
x_{1} \in C, \quad x_{n+1}=\left(1-\alpha_{n}\right) x_{n}+\alpha_{n} T^{n} x_{n}, \quad \forall n \geq 1,
$$

where $\left\{\alpha_{n}\right\}$ is a sequence in the interval $(0,1)$ and $T: C \rightarrow C$ is an asymptotically nonexpansive mapping.

In 1991, Schu [8] obtained the following results.

Theorem Schu 1. Let $E$ be a uniformly convex Banach space, $\emptyset \neq C \subset E$ closed bounded and convex, and $T: C \rightarrow C$ asymptotically nonexpansive with sequence $\left\{k_{n}\right\} \subset[1, \infty)$ for which $\sum_{n=1}^{\infty}\left(k_{n}-1\right)<\infty$ and $\left\{\alpha_{n}\right\} \in[0,1]$ is bounded away. Let $\left\{x_{n}\right\}$ be a sequence generated in (1.13). Then $\lim _{n \rightarrow \infty}\left\|x_{n}-T x_{n}\right\|=0$. 
Theorem Schu 2. Let E be a uniformly convex Banach space, $\emptyset \neq C \subset E$ closed bounded and convex, and $T: C \rightarrow C$ asymptotically nonexpansive with sequence $\left\{k_{n}\right\} \subset[1, \infty)$ for which $\sum_{n=1}^{\infty}\left(k_{n}-1\right)<$ $\infty$ and $\left\{\alpha_{n}\right\} \in[0,1]$ is bounded away. Let $\left\{x_{n}\right\}$ be a sequence generated in (1.13). Suppose that $T^{m}$ is compact for some positive integer $m \geq 1$. Then the sequence $\left\{x_{n}\right\}$ converges strongly to some fixed point of $T$.

Theorem Schu 3. Let $E$ be a uniformly convex Banach space, $\emptyset \neq C \subset E$ closed bounded and convex, and $T: C \rightarrow C$ asymptotically nonexpansive with sequence $\left\{k_{n}\right\} \subset[1, \infty)$ for which $\sum_{n=1}^{\infty}\left(k_{n}-1\right)<$ $\infty$ and $\left\{\alpha_{n}\right\} \in[0,1]$ is bounded away. Let $\left\{x_{n}\right\}$ be a sequence generated in (1.13). Suppose that there exists a nonempty compact and convex subset $K$ of $E$ and $\lambda \in(0,1)$ such that

$$
d(T x, K) \leq \lambda d(x, K), \quad \forall x \in C
$$

Then the sequence $\left\{x_{n}\right\}$ converges strongly to some fixed point of T.

In 2007, Shahzad and Zegeye [6] considered the following implicit iterative process for a finite family of generalized asymptotically quasi-nonexpansive mappings $\left\{T_{1}, T_{2}, \ldots, T_{N}\right\}$ :

$$
\begin{aligned}
x_{1} & =\alpha_{1} x_{0}+\left(1-\alpha_{1}\right) T_{1} x_{1}, \\
x_{2} & =\alpha_{2} x_{1}+\left(1-\alpha_{2}\right) T_{2} x_{2}, \\
& \vdots \\
x_{N} & =\alpha_{N} x_{N-1}+\left(1-\alpha_{N}\right) T_{N} x_{N}, \\
x_{N+1} & =\alpha_{N+1} x_{N}+\left(1-\alpha_{N+1}\right) T_{1}^{2} x_{N+1}, \\
& \vdots \\
x_{2 N} & =\alpha_{2 N} x_{2 N-1}+\left(1-\alpha_{2 N}\right) T_{N}^{2} x_{2 N}, \\
x_{2 N+1} & =\alpha_{2 N+1} x_{2 N}+\left(1-\alpha_{2 N+1}\right) T_{1}^{3} x_{2 N+1}, \\
& \vdots
\end{aligned}
$$

where $x_{0}$ is the initial value and $\left\{\alpha_{n}\right\}$ is a sequence $(0,1)$. Since for each $n \geq 1$, it can be written as $n=(h-1) N+i$, where $i=i(n) \in\{1,2, \ldots, N\}, h=h(n) \geq 1$ is a positive integer, and $h(n) \rightarrow \infty$ as $n \rightarrow \infty$. Hence the above table can be rewritten in the following compact form:

$$
x_{n}=\alpha_{n} x_{n-1}+\alpha_{n} T_{i(n)}^{h(n)} x_{n}, \quad \forall n \geq 1 .
$$

We remark that the implicit iterative process (1.16) was first considered by Sun [9]; see [9] for more details. 
Shahzad and Zegeye [6] obtained the following results.

Theorem SZ 1. Let $E$ be a real uniformly convex Banach space and $C$ be a nonempty closed convex subset of E. Let $\left\{T_{i}: i \in J\right\}$, where $J=\{1,2, \ldots, N\}$, be $N$ uniformly Lipschitz, generalized asymptotically quasi-nonexpansive self-mappings of $C$ with $\left\{k_{i n}\right\} \subset[1, \infty),\left\{\xi_{n}\right\} \subset[0, \infty)$ such that $\sum_{n=1}^{\infty}\left(k_{i n}-1\right)<\infty$ and $\sum_{n=1}^{\infty} \xi_{i n}<\infty$ for all $i \in J$. Suppose that $F=\cap_{i=1}^{N} F\left(T_{i}\right) \neq \emptyset$ and there exists one member $T$ in $\left\{T_{i}: i \in J\right\}$ which is either semicompact or satisfies condition $(\bar{C})$. Let $\left\{\alpha_{n}\right\} \subset[\delta, 1-\delta]$ for some $\delta \in(0,1)$. From arbitrary $x_{1} \in C$, define the sequence $\left\{x_{n}\right\}$ by (1.16). Then $\left\{x_{n}\right\}$ converges strongly to a common fixed point of the mappings $\left\{T_{i}: i \in J\right\}$.

Theorem SZ 2. Let $E$ be a real uniformly convex Banach space and $C$ a nonemptyclosed convex subset of $E$. Let $\left\{T_{i}: i \in J\right\}$, where $J=\{1,2, \ldots, N\}$, be $N$ generalized asymptotically quasinonexpansive self-mappings of $C$ with $\left\{k_{i n}\right\} \subset[1, \infty),\left\{\xi_{i n}\right\} \subset[0, \infty)$ such that $\sum_{n=1}^{\infty}\left(k_{i n}-1\right)<\infty$ and $\sum_{n=1}^{\infty} \xi_{i n}<\infty$ for all $i \in J$. Suppose that $F=\cap_{i=1}^{N} F\left(T_{i}\right) \neq \emptyset$ is closed. Let $\left\{\alpha_{n}\right\} \subset[\delta, 1-\delta]$ for some $\delta \in(0,1)$. From arbitrary $x_{1} \in C$, define the sequence $\left\{x_{n}\right\}$ by (1.16). Then $\left\{x_{n}\right\}$ converges strongly to a common fixed point of the mappings $\left\{T_{i}: i \in J\right\}$ if and only if $\liminf _{n \rightarrow \infty} d\left(x_{n}, F\right)=0$.

In this paper, motivated by the above results, we consider the following implicit iterative process for two finite families of generalized asymptotically quasi-nonexpansive mappings $\left\{S_{1}, S_{2}, \ldots, S_{N}\right\}$ and $\left\{T_{1}, T_{2}, \ldots, T_{N}\right\}$ :

$$
\begin{aligned}
x_{1} & =\alpha_{1} x_{0}+\beta_{1} S_{1} x_{0}+\gamma_{1} T_{1} x_{1}+\delta_{1} u_{1}, \\
x_{2} & =\alpha_{2} x_{1}+\beta_{2} S_{2} x_{1}+\gamma_{2} T_{2} x_{2}+\delta_{2} u_{2}, \\
& \vdots \\
x_{N} & =\alpha_{N} x_{N-1}+\beta_{N} S_{N} x_{N-1}+\gamma_{N} T_{N} x_{N}+\delta_{N} u_{N}, \\
x_{N+1} & =\alpha_{N+1} x_{N}+\beta_{N+1} S_{1}^{2} x_{N}+\gamma_{N+1} T_{1}^{2} x_{N+1}+\delta_{N+1} u_{N+1}, \\
& \vdots \\
x_{2 N} & =\alpha_{2 N} x_{2 N-1}+\beta_{2 N} S_{N}^{2} x_{2 N-1}+\gamma_{2 N} T_{N}^{2} x_{2 N}+\delta_{2 N} u_{2 N}, \\
x_{2 N+1} & =\alpha_{2 N+1} x_{2 N}+\beta_{2 N+1} S_{1}^{3} x_{2 N}+\gamma_{2 N+1} T_{1}^{3} x_{2 N+1}+\delta_{2 N+1} u_{2 N+1}, \\
& \vdots
\end{aligned}
$$

where $x_{0}$ is the initial value, $\left\{u_{n}\right\}$ is a bounded sequence in $C$, and $\left\{\alpha_{n}\right\},\left\{\beta_{n}\right\},\left\{\gamma_{n}\right\}$, and $\left\{\delta_{n}\right\}$ are sequences $(0,1)$ such that $\alpha_{n}+\beta_{n}+\gamma_{n}+\delta_{n}=1$ for each $n \geq 1$. Since for each $n \geq 1$, it can be written as $n=(h-1) N+i$, where $i=i(n) \in\{1,2, \ldots, N\}, h=h(n) \geq 1$ is a positive integer and $h(n) \rightarrow \infty$ as $n \rightarrow \infty$. Hence the above table can be rewritten in the following compact form:

$$
x_{n}=\alpha_{n} x_{n-1}+\beta_{n} S_{i(n)}^{h(n)} x_{n-1}+\gamma_{n} T_{i(n)}^{h(n)} x_{n}+\delta_{n} u_{n}, \quad \forall n \geq 1 .
$$


We remark that our implicit iterative process (1.18) which includes the explicit iterative process (1.13) and the implicit iterative process (1.16) as special cases is general.

If $S_{i}=I$, where $I$ denotes the identity mapping, for each $i \in\{1,2, \ldots, N\}$, then the implicit iterative process (1.18) is reduced to the following implicit iterative process:

$$
x_{n}=\left(\alpha_{n}+\beta_{n}\right) x_{n-1}+\gamma_{n} T_{i(n)}^{h(n)} x_{n}+\delta_{n} u_{n}, \quad \forall n \geq 1
$$

If $T_{i}=I$, where $I$ denotes the identity mapping, for each $i \in\{1,2, \ldots, N\}$, then the implicit iterative process (1.18) is reduced to the following explicit iterative process:

$$
x_{n}=\frac{\alpha_{n}}{1-\gamma_{n}} x_{n-1}+\frac{\beta_{n}}{1-\gamma_{n}} S_{i(n)}^{h(n)} x_{n-1}+\frac{\delta_{n}}{1-\gamma_{n}} u_{n}, \quad \forall n \geq 1
$$

The purpose of this paper is to study the convergence of the implicit iteration process (1.18) for two finite families of generalized asymptotically quasi-nonexpansive mappings. Strong convergence theorems are obtained in the framework of real Banach spaces. The results presented in this paper improve and extend the corresponding results in Shahzad and Zegeye [6], Sun [9], Chang et al. [10], Chidume and Shahzad [11], Guo and Cho [12], Kim et al. [13], Qin et al. [14], Thianwan and Suantai [15], Xu and Ori [16], and Zhou and Chang [17].

In order to prove our main results, we also need the following lemmas.

Lemma 1.2 (see [18]). Let $\left\{r_{n}\right\},\left\{s_{n}\right\}$, and $\left\{t_{n}\right\}$ be three nonnegative sequences satisfying the following condition:

$$
r_{n+1} \leq\left(1+s_{n}\right) r_{n}+t_{n}, \quad \forall n \geq n_{0}
$$

where $n_{0}$ is some positive integer. If $\sum_{n=1}^{\infty} s_{n}<\infty$ and $\sum_{n=1}^{\infty} t_{n}<\infty$, then $\lim _{n \rightarrow \infty} r_{n}$ exists.

Lemma 1.3 (see [19]). Let $E$ be a real uniformly convex Banach space, $s>0$ a positive number, and $B_{S}(0)$ a closed ball of $E$. Then there exists a continuous, strictly increasing, and convex function $g:[0, \infty) \rightarrow[0, \infty)$ with $g(0)=0$ such that

$$
\|a x+b y+c z+d w\|^{2} \leq a\|x\|^{2}+b\|y\|^{2}+c\|z\|^{2}+d\|w\|^{2}-a b g(\|x-y\|)
$$

for all $x, y, z, w \in B_{s}(0)=\{x \in E:\|x\| \leq s\}$ and $a, b, c, d \in[0,1]$ such that $a+b+c+d=1$.

\section{Main Results}

Lemma 2.1. Let $E$ be a real uniformly convex Banach space and $C$ a nonempty closed convex subset of $E$. Let $T_{i}: C \rightarrow C$ be a uniformly $L_{t, i}$-Lipschitz and generalized asymptotically quasi-nonexpansive mapping with sequences $\left\{k_{n, t, i}\right\} \subset[1, \infty)$ and $\left\{\xi_{n, t, i}\right\} \subset[0, \infty)$ such that $\sum_{n=1}^{\infty}\left(k_{n, t, i}-1\right)<\infty$ and $\sum_{n=1}^{\infty} \xi_{n, t, i}<\infty$ for each $1 \leq i \leq N$ and $S_{i}: C \rightarrow C$ a uniformly $L_{s, i}$-Lipschitz and generalized asymptotically quasi-nonexpansive mapping with sequences $\left\{k_{n, s, i}\right\} \subset[1, \infty)$ and $\left\{\xi_{n, s, i}\right\} \subset[0, \infty)$ such that $\sum_{n=1}^{\infty}\left(k_{n, s, i}-1\right)<\infty$ and $\sum_{n=1}^{\infty} \xi_{n, s, i}<\infty$ for each $1 \leq i \leq N$. Assume that $F=$ 
$\cap_{i=1}^{N} F\left(T_{i}\right) \cap \cap_{i=1}^{N} F\left(S_{i}\right)$ is nonempty. Let $\left\{u_{n}\right\}$ be a bounded sequence in $C, k_{n}=\max \left\{k_{n, t}, k_{n, s}\right\}$, where $k_{n, t}=\max \left\{k_{n, t, i}: 1 \leq i \leq N\right\}$ and $k_{n, s}=\max \left\{k_{n, s, i}: 1 \leq i \leq N\right\}$ and $\xi_{n}=\max \left\{\xi_{n, t}, \xi_{n, s}\right\}$, where $\xi_{n, t}=\max \left\{\xi_{n, t, i}: 1 \leq i \leq N\right\}$ and $\xi_{n, s}=\max \left\{\xi_{n, s, i}: 1 \leq i \leq N\right\}$. Let $\left\{\alpha_{n}\right\},\left\{\beta_{n}\right\},\left\{\gamma_{n}\right\}$, and $\left\{\delta_{n}\right\}$ be sequences in $(0,1)$ such that $\alpha_{n}+\beta_{n}+\gamma_{n}+\delta_{n}=1$ for each $n \geq 1$. Let $\left\{x_{n}\right\}$ be a sequence generated in (1.18). Assume that the following restrictions are satisfied:

(a) there exist constants $a, b, c, d \in(0,1)$ such that $a \leq \alpha_{n}, b \leq \beta_{n}$, and $c \leq \gamma_{n} \leq d<1 / L_{t}$, where $L_{t}=\max \left\{L_{t, i}: 1 \leq i \leq N\right\}$, for all $n \geq 1$;

(b) $\sum_{n=1}^{\infty} \delta_{n}<\infty$.

Then

$$
\lim _{n \rightarrow \infty}\left\|x_{n}-T_{r} x_{n}\right\|=\lim _{n \rightarrow \infty}\left\|x_{n}-S_{r} x_{n}\right\|=0, \quad \forall r \in\{1,2, \ldots, N\}
$$

Proof. First, we show that the sequence $\left\{x_{n}\right\}$ generated in (1.18) is well defined. For each $n \geq 1$, define a mapping $C_{n}: C \rightarrow C$ as follows:

$$
C_{n} x=\alpha_{n} x_{n-1}+\beta_{n} S_{i(n)}^{h(n)} x_{n-1}+\gamma_{n} T_{i(n)}^{h(n)} x+\delta_{n} u_{n}, \quad \forall x \in C
$$

Notice that

$$
\begin{aligned}
\left\|C_{n} x-C_{n} y\right\| & \leq \gamma_{n}\left\|T_{i(n)}^{h(n)} x-T_{i(n)}^{h(n)} y\right\| \\
& \leq d L_{t}\|x-y\|, \quad \forall x, y \in C .
\end{aligned}
$$

From the restriction (a), we see that $C_{n}$ is a contraction for each $n \geq 1$. From Banach contraction mapping principle, we can prove that the sequence $\left\{x_{n}\right\}$ generated in (1.18) is well defined.

Fixing $p \in F$, we see that

$$
\begin{aligned}
\left\|x_{n}-p\right\| \leq & \alpha_{n}\left\|x_{n-1}-p\right\|+\beta_{n}\left\|S_{i(n)}^{h(n)} x_{n-1}-p\right\|+\gamma_{n}\left\|T_{i(n)}^{h(n)} x_{n}-p\right\|+\delta_{n}\left\|u_{n}-p\right\| \\
\leq & \alpha_{n}\left\|x_{n-1}-p\right\|+\beta_{n}\left(k_{h(n)}\left\|x_{n-1}-p\right\|+\xi_{h(n)}\right)+\gamma_{n}\left(k_{h(n)}\left\|x_{n}-p\right\|+\xi_{h(n)}\right) \\
& +\delta_{n}\left\|u_{n}-p\right\| \\
\leq & \left(\alpha_{n}+\beta_{n} k_{h(n)}\right)\left\|x_{n-1}-p\right\|+\left(1-\alpha_{n}-\beta_{n}\right) k_{h(n)}\left\|x_{n}-p\right\|+2 \xi_{h(n)} \\
& +\delta_{n}\left\|u_{n}-p\right\| .
\end{aligned}
$$

Notice that $\sum_{n=1}^{\infty}\left(k_{n}-1\right)<\infty$. We see from the restrictions (a) and (b) that there exists a positive integer $n_{0}$ such that

$$
\left(1-\alpha_{n}-\beta_{n}\right) k_{h(n)} \leq R<1, \quad \forall n \geq n_{0}
$$


where $R=(1-(a+b))(1+(a+b) /(2-2(a+b)))$. It follows from (2.4) that

$$
\begin{aligned}
\left\|x_{n}-p\right\| \leq & \frac{\alpha_{n}+\beta_{n} k_{h(n)}}{1-\left(1-\alpha_{n}-\beta_{n}\right) k_{h(n)}}\left\|x_{n-1}-p\right\|+\frac{\delta_{n}}{1-\left(1-\alpha_{n}-\beta_{n}\right) k_{h(n)}}\left\|u_{n}-p\right\| \\
& +\frac{2 \xi_{h(n)}}{1-\left(1-\alpha_{n}-\beta_{n}\right) k_{h(n)}} \\
\leq & \left(1+\frac{k_{h(n)}-1}{1-R}\right)\left\|x_{n-1}-p\right\|+\frac{\delta_{n}}{1-R}\left\|u_{n}-p\right\|+\frac{2 \xi_{h(n)}}{1-R} \\
\leq & \left(1+\frac{k_{h(n)}-1}{1-R}\right)\left\|x_{n-1}-p\right\|+M_{1}\left(\delta_{n}+\xi_{h(n)}\right), \quad \forall n \geq n_{0},
\end{aligned}
$$

where $M_{1}$ is an appropriate constant such that $M_{1}=\max \left\{\sup _{n \geq 1}\left\{\left\|u_{n}-p\right\| /(1-R)\right\}, 2 /(1-R)\right\}$. In view of the restrictions (a) and (b), we obtain from Lemma 1.2 that $\lim _{n \rightarrow \infty}\left\|x_{n}-p\right\|$ exists. It follows that the sequence $\left\{x_{n}\right\}$ is bounded. In view of Lemma 1.3, we see that

$$
\begin{aligned}
\left\|x_{n}-p\right\|^{2} \leq & \alpha_{n}\left\|x_{n-1}-p\right\|^{2}+\beta_{n}\left\|S_{i(n)}^{h(n)} x_{n-1}-p\right\|^{2}+\gamma_{n}\left\|T_{i(n)}^{h(n)} x_{n}-p\right\|^{2} \\
& +\delta_{n}\left\|u_{n}-p\right\|^{2}-\alpha_{n} \beta_{n} g\left(\left\|S_{i(n)}^{h(n)} x_{n-1}-x_{n-1}\right\|\right) \\
\leq & \alpha_{n}\left\|x_{n-1}-p\right\|^{2}+\beta_{n}\left(k_{h(n)}\left\|x_{n-1}-p\right\|+\xi_{h(n)}\right)^{2}+\gamma_{n}\left(k_{h(n)}\left\|x_{n}-p\right\|+\xi_{h(n)}\right)^{2} \\
& +\delta_{n}\left\|u_{n}-p\right\|^{2}-\alpha_{n} \beta_{n} g\left(\left\|S_{i(n)}^{h(n)} x_{n-1}-x_{n-1}\right\|\right) \\
\leq & \alpha_{n}\left\|x_{n-1}-p\right\|^{2}+\beta_{n}\left(k_{h(n)}^{2}\left\|x_{n-1}-p\right\|^{2}+\xi_{h(n)}^{2}+2 k_{h(n)} \xi_{h(n)}\left\|x_{n-1}-p\right\|\right) \\
& +\gamma_{n}\left(k_{h(n)}^{2}\left\|x_{n}-p\right\|^{2}+\xi_{h(n)}^{2}+2 k_{h(n)} \xi_{h(n)}\left\|x_{n}-p\right\|\right) \\
& +\delta_{n}\left\|u_{n}-p\right\|^{2}-\alpha_{n} \beta_{n} g\left(\left\|S_{i(n)}^{h(n)} x_{n-1}-x_{n-1}\right\|\right) \\
\leq & \left(\alpha_{n}+\beta_{n} k_{h(n)}^{2}\right)\left\|x_{n-1}-p\right\|^{2}+\gamma_{n} k_{h(n)}^{2}\left\|x_{n}-p\right\|^{2}+2 \xi_{h(n)}^{2} \\
& +2 k_{h(n)} \xi \xi_{h(n)} M_{2}+\delta_{n} M_{3}-\alpha_{n} \beta_{n} g\left(\left\|S_{i(n)}^{h(n)} x_{n-1}-x_{n-1}\right\|\right),
\end{aligned}
$$

where $M_{2}$ and $M_{3}$ are appropriate constants such that $M_{2}=\sup _{n \geq 1}\left\{\left\|x_{n}-p\right\|+\left\|x_{n-1}-p\right\|\right\}$ and $M_{3}=\sup _{n \geq 1}\left\{\left\|u_{n}-p\right\|^{2}\right\}$. This implies that

$$
\begin{aligned}
\alpha_{n} \beta_{n} g & \left(\left\|S_{i(n)}^{h(n)} x_{n-1}-x_{n-1}\right\|\right) \\
\leq & \left(\alpha_{n}+\beta_{n} k_{h(n)}^{2}\right)\left(\left\|x_{n-1}-p\right\|^{2}-\left\|x_{n}-p\right\|^{2}\right)+\left(k_{h(n)}^{2}-1\right)\left\|x_{n}-p\right\|^{2} \\
& +2 \xi_{h(n)}^{2}+2 k_{h(n)} \xi_{h(n)} M_{2}+\delta_{n} M_{3} .
\end{aligned}
$$


In view of the restrictions (a) and (b), we obtain that

$$
\lim _{n \rightarrow \infty} g\left(\left\|S_{i(n)}^{h(n)} x_{n-1}-x_{n-1}\right\|\right)=0
$$

Since $g:[0, \infty) \rightarrow[0, \infty)$ is a continuous, strictly increasing, and convex function with $g(0)=0$, we obtain that

$$
\lim _{n \rightarrow \infty}\left\|S_{i(n)}^{h(n)} x_{n-1}-x_{n-1}\right\|=0
$$

Next, we show that

$$
\lim _{n \rightarrow \infty}\left\|T_{i(n)}^{h(n)} x_{n}-x_{n-1}\right\|=0
$$

From Lemma 1.3, we also see that

$$
\begin{aligned}
\left\|x_{n}-p\right\|^{2} \leq & \alpha_{n}\left\|x_{n-1}-p\right\|^{2}+\beta_{n}\left\|S_{i(n)}^{h(n)} x_{n-1}-p\right\|^{2}+\gamma_{n}\left\|T_{i(n)}^{h(n)} x_{n}-p\right\|^{2} \\
& +\delta_{n}\left\|u_{n}-p\right\|^{2}-\alpha_{n} \gamma_{n} g\left(\left\|T_{i(n)}^{h(n)} x_{n}-x_{n-1}\right\|\right) \\
\leq & \alpha_{n}\left\|x_{n-1}-p\right\|^{2}+\beta_{n}\left(k_{h(n)}\left\|x_{n-1}-p\right\|+\xi_{h(n)}\right)^{2}+\gamma_{n}\left(k_{h(n)}\left\|x_{n}-p\right\|+\xi_{h(n)}\right)^{2} \\
& +\delta_{n}\left\|u_{n}-p\right\|^{2}-\alpha_{n} \gamma_{n} g\left(\left\|T_{i(n)}^{h(n)} x_{n}-x_{n-1}\right\|\right) \\
\leq & \alpha_{n}\left\|x_{n-1}-p\right\|^{2}+\beta_{n}\left(k_{h(n)}^{2}\left\|x_{n-1}-p\right\|^{2}+\xi_{h(n)}^{2}+2 k_{h(n)} \xi_{h(n)}\left\|x_{n-1}-p\right\|\right) \\
& +\gamma_{n}\left(k_{h(n)}^{2}\left\|x_{n}-p\right\|^{2}+\xi_{h(n)}^{2}+2 k_{h(n)} \xi_{h(n)}\left\|x_{n}-p\right\|\right) \\
& +\delta_{n}\left\|u_{n}-p\right\|^{2}-\alpha_{n} \gamma_{n} g\left(\left\|T_{i(n)}^{h(n)} x_{n}-x_{n-1}\right\|\right) \\
\leq & \left(\alpha_{n}+\beta_{n} k_{h(n)}^{2}\right)\left\|x_{n-1}-p\right\|^{2}+\gamma_{n} k_{h(n)}^{2}\left\|x_{n}-p\right\|^{2}+2 \xi_{h(n)}^{2} \\
& +2 k_{h(n)} \xi_{h(n)} M_{2}+\delta_{n} M_{3}-\alpha_{n} \gamma_{n} g\left(\left\|T_{i(n)}^{h(n)} x_{n}-x_{n-1}\right\|\right) .
\end{aligned}
$$

This implies that

$$
\begin{aligned}
\alpha_{n} \gamma_{n} g & \left(\left\|T_{i(n)}^{h(n)} x_{n}-x_{n-1}\right\|\right) \\
\leq & \left(\alpha_{n}+\beta_{n} k_{h(n)}^{2}\right)\left(\left\|x_{n-1}-p\right\|^{2}-\left\|x_{n}-p\right\|^{2}\right)+\left(k_{h(n)}^{2}-1\right)\left\|x_{n}-p\right\|^{2} \\
& +2 \xi_{h(n)}^{2}+2 k_{h(n)} \xi_{h(n)} M_{2}+\delta_{n} M_{3} .
\end{aligned}
$$


In view of the restrictions (a) and (b), we obtain that

$$
\lim _{n \rightarrow \infty} g\left(\left\|T_{i(n)}^{h(n)} x_{n}-x_{n-1}\right\|\right)=0 .
$$

Since $g:[0, \infty) \rightarrow[0, \infty)$ is a continuous, strictly increasing, and convex function with $g(0)=0$, we obtain that $(2.11)$ holds. Notice that

$$
\left\|x_{n}-x_{n-1}\right\| \leq\left\|S_{i(n)}^{h(n)} x_{n-1}-x_{n-1}\right\|+\left\|T_{i(n)}^{h(n)} x_{n}-x_{n-1}\right\|+\delta_{n}\left\|u_{n}-x_{n-1}\right\| .
$$

In view of (2.10) and (2.11), we see from the restriction $(b)$ that

$$
\lim _{n \rightarrow \infty}\left\|x_{n}-x_{n-1}\right\|=0
$$

which implies that

$$
\lim _{n \rightarrow \infty}\left\|x_{n}-x_{n+j}\right\|=0, \quad \forall j \in\{1,2, \ldots, N\} .
$$

Since for any positive integer $n>N$, it can be written as $n=(h(n)-1) N+i(n)$, where $i(n) \in\{1,2, \ldots, N\}$, observe that

$$
\begin{aligned}
\left\|x_{n-1}-T_{n} x_{n}\right\| \leq & \left\|x_{n-1}-T_{i(n)}^{h(n)} x_{n}\right\|+\left\|T_{i(n)}^{h(n)} x_{n}-T_{n} x_{n}\right\| \\
\leq & \left\|x_{n-1}-T_{i(n)}^{h(n)} x_{n}\right\|+L_{t}\left\|T_{i(n)}^{h(n)-1} x_{n}-x_{n}\right\| \\
\leq & \left\|x_{n-1}-T_{i(n)}^{h(n)} x_{n}\right\| \\
& +L_{t}\left(\left\|T_{i(n)}^{h(n)-1} x_{n}-T_{i(n-N)}^{h(n)-1} x_{n-N}\right\|+\left\|T_{i(n-N)}^{h(n)-1} x_{n-N}-x_{(n-N)-1}\right\|\right. \\
& \left.+\left\|x_{(n-N)-1}-x_{n}\right\|\right) .
\end{aligned}
$$

Since for each $n>N, n=(n-N)(\bmod N)$, on the other hand, we obtain from $n=(h(n)-$ 1) $N+i(n)$ that $n-N=((h(n)-1)-1) N+i(n)=(h(n-N)-1) N+i(n-N)$. That is,

$$
h(n-N)=h(n)-1, \quad i(n-N)=i(n) .
$$

Notice that

$$
\begin{aligned}
\left\|T_{i(n)}^{h(n)-1} x_{n}-T_{i(n-N)}^{h(n)-1} x_{n-N}\right\| & =\left\|T_{i(n)}^{h(n)-1} x_{n}-T_{i(n)}^{h(n)-1} x_{n-N}\right\| \\
& \leq L t\left\|x_{n}-x_{n-N}\right\|, \\
\left\|T_{i(n-N)}^{h(n)-1} x_{n-N}-x_{(n-N)-1}\right\| & =\left\|T_{i(n-N)}^{h(n-N)} x_{n-N}-x_{(n-N)-1}\right\| .
\end{aligned}
$$


Fixed Point Theory and Applications

Substituting (2.20) into (2.18), we arrive at

$$
\begin{aligned}
\left\|x_{n-1}-T_{n} x_{n}\right\| \leq & \left\|x_{n-1}-T_{i(n)}^{h(n)} x_{n}\right\| \\
& +L_{t}\left(L_{t}\left\|x_{n}-x_{n-N}\right\|+\left\|T_{i(n-N)}^{h(n-N)} x_{n-N}-x_{(n-N)-1}\right\|+\left\|x_{(n-N)-1}-x_{n}\right\|\right) .
\end{aligned}
$$

In view of (2.11) and (2.17), we obtain that

$$
\lim _{n \rightarrow \infty}\left\|x_{n-1}-T_{n} x_{n}\right\|=0
$$

Notice that

$$
\left\|x_{n}-T_{n} x_{n}\right\| \leq\left\|x_{n}-x_{n-1}\right\|+\left\|x_{n-1}-T_{n} x_{n}\right\| .
$$

It follows from (2.16) and (2.22) that

$$
\lim _{n \rightarrow \infty}\left\|x_{n}-T_{n} x_{n}\right\|=0
$$

Notice that

$$
\begin{aligned}
\left\|x_{n}-T_{n+j} x_{n}\right\| & \leq\left\|x_{n}-x_{n+j}\right\|+\left\|x_{n+j}-T_{n+j} x_{n+j}\right\|+\left\|T_{n+j} x_{n+j}-T_{n+j} x_{n}\right\| \\
& \leq\left(1+L_{t}\right)\left\|x_{n}-x_{n+j}\right\|+\left\|x_{n+j}-T_{n+j} x_{n+j}\right\|, \quad \forall j \in\{1,2, \ldots, N\} .
\end{aligned}
$$

From (2.17) and (2.24), we arrive at

$$
\lim _{n \rightarrow \infty}\left\|x_{n}-T_{n+j} x_{n}\right\|=0, \quad \forall j \in\{1,2, \ldots, N\} .
$$

Note that any subsequence of a convergent number sequence converges to the same limit. It follows that

$$
\lim _{n \rightarrow \infty}\left\|x_{n}-T_{r} x_{n}\right\|=0, \quad \forall r \in\{1,2, \ldots, N\}
$$

Letting $L_{s}=\max \left\{L_{s, i}: 1 \leq i \leq N\right\}$, we have

$$
\begin{aligned}
\left\|S_{i(n)}^{h(n)} x_{n}-x_{n-1}\right\| & \leq\left\|S_{i(n)}^{h(n)} x_{n}-S_{i(n)}^{h(n)} x_{n-1}\right\|+\left\|S_{i(n)}^{h(n)} x_{n-1}-x_{n-1}\right\| \\
& \leq L_{s}\left\|x_{n}-x_{n-1}\right\|+\left\|S_{i(n)}^{h(n)} x_{n-1}-x_{n-1}\right\| .
\end{aligned}
$$

In view of (2.10) and (2.16), we see that

$$
\lim _{n \rightarrow \infty}\left\|S_{i(n)}^{h(n)} x_{n}-x_{n-1}\right\|=0
$$


Observe that

$$
\begin{aligned}
\left\|x_{n-1}-S_{n} x_{n-1}\right\| \leq & \left\|x_{n-1}-S_{i(n)}^{h(n)} x_{n-1}\right\|+\left\|S_{i(n)}^{h(n)} x_{n-1}-S_{n} x_{n-1}\right\| \\
\leq & \left\|x_{n-1}-S_{i(n)}^{h(n)} x_{n-1}\right\|+L_{S}\left\|S_{i(n)}^{h(n)-1} x_{n-1}-x_{n-1}\right\| \\
\leq & \left\|x_{n-1}-S_{i(n)}^{h(n)} x_{n-1}\right\| \\
& +L_{S}\left(\left\|S_{i(n)}^{h(n)-1} x_{n-1}-S_{i(n-N)}^{h(n)-1} x_{n-N}\right\|+\left\|S_{i(n-N)}^{h(n)-1} x_{n-N}-x_{(n-N)-1}\right\|\right. \\
& \left.+\left\|x_{(n-N)-1}-x_{n-1}\right\|\right) .
\end{aligned}
$$

In view of

$$
\begin{aligned}
\left\|S_{i(n)}^{h(n)-1} x_{n-1}-S_{i(n-N)}^{h(n)-1} x_{n-N}\right\| & =\left\|S_{i(n)}^{h(n)-1} x_{n-1}-S_{i(n)}^{h(n)-1} x_{n-N}\right\| \\
& \leq L_{s}\left\|x_{n-1}-x_{n-N}\right\|, \\
\left\|S_{i(n-N)}^{h(n)-1} x_{n-N}-x_{(n-N)-1}\right\| & =\left\|S_{i(n-N)}^{h(n-N)} x_{n-N}-x_{(n-N)-1}\right\|,
\end{aligned}
$$

we arrive at

$$
\begin{aligned}
\left\|x_{n-1}-S_{n} x_{n-1}\right\| \leq & \left\|x_{n-1}-S_{i(n)}^{h(n)} x_{n-1}\right\| \\
& +L_{S}\left(L_{s}\left\|x_{n-1}-x_{n-N}\right\|+\left\|S_{i(n-N)}^{h(n-N)} x_{n-N}-x_{(n-N)-1}\right\|+\left\|x_{(n-N)-1}-x_{n-1}\right\|\right) .
\end{aligned}
$$

In view of (2.10), (2.17), and (2.29), we obtain that

$$
\lim _{n \rightarrow \infty}\left\|x_{n-1}-S_{n} x_{n-1}\right\|=0 .
$$

Notice that

$$
\begin{aligned}
\left\|x_{n}-S_{n} x_{n}\right\| & \leq\left\|x_{n}-x_{n-1}\right\|+\left\|x_{n-1}-S_{n} x_{n-1}\right\|+\left\|S_{n} x_{n-1}-S_{n} x_{n}\right\| \\
& \leq\left(1+L_{S}\right)\left\|x_{n}-x_{n-1}\right\|+\left\|x_{n-1}-S_{n} x_{n-1}\right\| .
\end{aligned}
$$

From (2.16) and (2.33), we see that

$$
\lim _{n \rightarrow \infty}\left\|x_{n}-S_{n} x_{n}\right\|=0 .
$$

On the other hand, we have

$$
\begin{aligned}
\left\|x_{n}-S_{n+j} x_{n}\right\| & \leq\left\|x_{n}-x_{n+j}\right\|+\left\|x_{n+j}-S_{n+j} x_{n+j}\right\|+\left\|S_{n+j} x_{n+j}-S_{n+j} x_{n}\right\| \\
& \leq\left(1+L_{s}\right)\left\|x_{n}-x_{n+j}\right\|+\left\|x_{n+j}-S_{n+j} x_{n+j}\right\|, \quad \forall j \in\{1,2, \ldots, N\} .
\end{aligned}
$$


It follows from (2.17) and (2.35) that

$$
\lim _{n \rightarrow \infty}\left\|x_{n}-S_{n+j} x_{n}\right\|=0, \quad \forall j \in\{1,2, \ldots, N\} .
$$

Note that any subsequence of a convergent number sequence converges to the same limit. It follows that

$$
\lim _{n \rightarrow \infty}\left\|x_{n}-S_{r} x_{n}\right\|=0, \quad \forall r \in\{1,2, \ldots, N\}
$$

This completes the proof.

Recall that a mapping $T: C \rightarrow C$ is said to be semicompact if for any bounded sequence $\left\{x_{n}\right\}$ in $C$ such that $\left\|x_{n}-T x_{n}\right\| \rightarrow 0$ as $n \rightarrow \infty$, then there exists a subsequence $\left\{x_{n_{i}}\right\} \subset\left\{x_{n}\right\}$ such that $x_{n_{i}} \rightarrow x \in C$.

Next, we give strong convergence theorems with the help of the semicompactness.

Theorem 2.2. Let $E$ be a real uniformly convex Banach space and $C$ a nonempty closed convex subset of $E$. Let $T_{i}: C \rightarrow C$ be a uniformly $L_{t, i}-$ Lipschitz and generalized asymptotically quasi-nonexpansive mapping with sequences $\left\{k_{n, t, i}\right\} \subset[1, \infty)$ and $\left\{\xi_{n, t, i}\right\} \subset[0, \infty)$ such that $\sum_{n=1}^{\infty}\left(k_{n, t, i}-1\right)<\infty$ and $\sum_{n=1}^{\infty} \xi_{n, t, i}<\infty$ for each $1 \leq i \leq N$, and let $S_{i}: C \rightarrow C$ be a uniformly $L_{s, i}$-Lipschitz and generalized asymptotically quasi-nonexpansive mapping with sequences $\left\{k_{n, s, i}\right\} \subset[1, \infty)$ and $\left\{\xi_{n, s, i}\right\} \subset[0, \infty)$ such that $\sum_{n=1}^{\infty}\left(k_{n, s, i}-1\right)<\infty$ and $\sum_{n=1}^{\infty} \xi_{n, s, i}<\infty$ for each $1 \leq i \leq N$. Assume that $F=\cap_{i=1}^{N} F\left(T_{i}\right) \cap \cap_{i=1}^{N} F\left(S_{i}\right)$ is nonempty. Let $\left\{u_{n}\right\}$ be a bounded sequence in $C, k_{n}=\max \left\{k_{n, t}, k_{n, s}\right\}$, where $k_{n, t}=\max \left\{k_{n, t, i}: 1 \leq i \leq N\right\}$ and $k_{n, s}=\max \left\{k_{n, s, i}: 1 \leq i \leq N\right\}$ and $\xi_{n}=\max \left\{\xi_{n, t}, \xi_{n, s}\right\}$, where $\xi_{n, t}=\max \left\{\xi_{n, t, i}: 1 \leq i \leq N\right\}$ and $\xi_{n, s}=\max \left\{\xi_{n, s, i}: 1 \leq i \leq N\right\}$. Let $\left\{\alpha_{n}\right\},\left\{\beta_{n}\right\},\left\{\gamma_{n}\right\}$, and $\left\{\delta_{n}\right\}$ be sequences in $(0,1)$ such that $\alpha_{n}+\beta_{n}+\gamma_{n}+\delta_{n}=1$ for each $n \geq 1$. Let $\left\{x_{n}\right\}$ be a sequence generated in (1.18). Assume that the following restrictions are satisfied:

(a) there exist constants $a, b, c, d \in(0,1)$ such that $a \leq \alpha_{n}, b \leq \beta_{n}$, and $c \leq \gamma_{n} \leq d<1 / L_{t}$, where $L_{t}=\max \left\{L_{t, i}: 1 \leq i \leq N\right\}$, for all $n \geq 1$;

(b) $\sum_{n=1}^{\infty} \delta_{n}<\infty$.

If one of $\left\{S_{1}, S_{2}, \ldots, S_{N}\right\}$ or one of $\left\{T_{1}, T_{2}, \ldots, T_{N}\right\}$ is semicompact, then the sequence $\left\{x_{n}\right\}$ converges strongly to some point in $F$.

Proof. Without loss of generality, we may assume that $S_{1}$ is semicompact. From (2.38), we see that there exits a subsequence $\left\{x_{n_{i}}\right\}$ of $\left\{x_{n}\right\}$ converging strongly to $x \in C$. For each $r \in$ $\{1,2, \ldots, N\}$, we get that

$$
\left\|x-S_{r} x\right\| \leq\left\|x-x_{n_{i}}\right\|+\left\|x_{n_{i}}-S_{r} x_{n_{i}}\right\|+\left\|S_{r} x_{n_{i}}-S_{r} x\right\| .
$$

Since $S_{r}$ is Lipshcitz continuous, we obtain from (2.38) that $x \in \cap_{r=1}^{N} F\left(S_{r}\right)$. Notice that

$$
\left\|x-T_{r} x\right\| \leq\left\|x-x_{n_{i}}\right\|+\left\|x_{n_{i}}-T_{r} x_{n_{i}}\right\|+\left\|T_{r} x_{n_{i}}-T_{r} x\right\| .
$$

Since $T_{r}$ is Lipshcitz continuous, we obtain from (2.27) that $x \in \cap_{r=1}^{N} F\left(T_{r}\right)$. This means that $x \in F$. In view of Lemma 2.1, we obtain that $\lim _{n \rightarrow \infty}\left\|x_{n}-x\right\|$ exists. Therefore, we can obtain the desired conclusion immediately. 
If $S_{i}=I$, where $I$ denotes the identity mapping, for each $i \in\{1,2, \ldots, N\}$, then Theorem 2.2 is reduced to the following.

Corollary 2.3. Let E be a real uniformly convex Banach space and $C$ a nonempty closed convex subset of E. Let $T_{i}: C \rightarrow C$ be a uniformly $L_{t, i}$-Lipschitz and generalized asymptotically quasi-nonexpansive mapping with sequences $\left\{k_{n, t, i}\right\} \subset[1, \infty)$ and $\left\{\xi_{n, t, i}\right\} \subset[0, \infty)$ such that $\sum_{n=1}^{\infty}\left(k_{n, t, i}-1\right)<\infty$ and $\sum_{n=1}^{\infty} \xi_{n, t, i}<\infty$ for each $1 \leq i \leq N$. Assume that $F=\cap_{i=1}^{N} F\left(T_{i}\right)$ is nonempty. Let $\left\{u_{n}\right\}$ be a bounded sequence in $C, k_{n, t}=\max \left\{k_{n, t, i}: 1 \leq i \leq N\right\}$, and $\xi_{n, t}=\max \left\{\xi_{n, t, i}: 1 \leq i \leq N\right\}$. Let $\left\{\alpha_{n}\right\},\left\{\beta_{n}\right\}$, $\left\{\gamma_{n}\right\}$, and $\left\{\delta_{n}\right\}$ be sequences in $(0,1)$ such that $\alpha_{n}+\beta_{n}+\gamma_{n}+\delta_{n}=1$ for each $n \geq 1$. Let $\left\{x_{n}\right\}$ be a sequence generated in (1.19). Assume that the following restrictions are satisfied:

(a) there exist constants $a, b, c \in(0,1)$ such that $a \leq \alpha_{n}+\beta_{n}$ and $b \leq \gamma_{n} \leq c<1 / L_{t}$, where $L_{t}=\max \left\{L_{t, i}: 1 \leq i \leq N\right\}$, for all $n \geq 1$;

(b) $\sum_{n=1}^{\infty} \delta_{n}<\infty$.

If one of $\left\{T_{1}, T_{2}, \ldots, T_{N}\right\}$ is semicompact, then the sequence converges $\left\{x_{n}\right\}$ strongly to some point in F.

If $T_{i}=I$, where $I$ denotes the identity mapping, for each $i \in\{1,2, \ldots, N\}$, then Theorem 2.2 is reduced to the following.

Corollary 2.4. Let E be a real uniformly convex Banach space and $C$ a nonempty closed convex subset of E. Let $S_{i}: C \rightarrow$ C be a uniformly $L_{s, i}$-Lipschitz and generalized asymptotically quasi-nonexpansive mapping with sequences $\left\{k_{n, s, i}\right\} \subset[1, \infty)$ and $\left\{\xi_{n, s, i}\right\} \subset[0, \infty)$ such that $\sum_{n=1}^{\infty}\left(k_{n, s, i}-1\right)<\infty$ and $\sum_{n=1}^{\infty} \xi_{n, s, i}<\infty$ for each $1 \leq i \leq N$. Assume that $F=\cap_{i=1}^{N} F\left(S_{i}\right)$ is nonempty. Let $\left\{u_{n}\right\}$ be a bounded sequence in $C, k_{n, s}=\max \left\{k_{n, s, i}: 1 \leq i \leq N\right\}$ and $\xi_{n, s}=\max \left\{\xi_{n, s, i}: 1 \leq i \leq N\right\}$. Let $\left\{\alpha_{n}\right\},\left\{\beta_{n}\right\}$, $\left\{\gamma_{n}\right\}$, and $\left\{\delta_{n}\right\}$ be sequences in $(0,1)$ such that $\alpha_{n}+\beta_{n}+\gamma_{n}+\delta_{n}=1$ for each $n \geq 1$. Let $\left\{x_{n}\right\}$ be a sequence generated in (1.20). Assume that the following restrictions are satisfied:

(a) there exist constants $a, b, c, d \in(0,1)$ such that $a \leq \alpha_{n}, b \leq \beta_{n}$, and $c \leq \gamma_{n}$, for all $n \geq 1$;

(b) $\sum_{n=1}^{\infty} \delta_{n}<\infty$.

If one of $\left\{S_{1}, S_{2}, \ldots, S_{N}\right\}$ is semicompact, then the sequence $\left\{x_{n}\right\}$ converges strongly to some point in F.

In 2005, Chidume and Shahzad [11] introduced the following conception. Recall that a family $\left\{T_{i}\right\}_{i=1}^{N}: C \rightarrow C$ with $F=\cap_{i=1}^{N} F\left(T_{i}\right) \neq \emptyset$ is said to satisfy Condition $(B)$ on $C$ if there is a nondecreasing function $f:[0, \infty) \rightarrow[0, \infty)$ with $f(0)=0$ and $f(m)>0$ for all $m \in(0, \infty)$ such that for all $x \in C$

$$
\max _{1 \leq i \leq N}\left\{\left\|x-T_{i} x\right\|\right\} \geq f(d(x, F))
$$

Based on Condition $(B)$, we introduced the following conception for two finite families of mappings. Recall that two families $\left\{S_{i}\right\}_{i=1}^{N}: C \rightarrow C$ and $\left\{T_{i}\right\}_{i=1}^{N}: C \rightarrow C$ with $F=\cap_{i=1}^{N} F\left(S_{i}\right) \cap \cap_{i=1}^{N} F\left(T_{i}\right) \neq \emptyset$ are said to satisfy Condition $\left(B^{\prime}\right)$ on $C$ if there is a nondecreasing function $f:[0, \infty) \rightarrow[0, \infty)$ with $f(0)=0$ and $f(m)>0$ for all $m \in(0, \infty)$ such that for all $x \in C$

$$
\max _{1 \leq i \leq N}\left\{\left\|x-S_{i} x\right\|\right\}+\max _{1 \leq i \leq N}\left\{\left\|x-T_{i} x\right\|\right\} \geq f(d(x, F))
$$


Next, we give strong convergence theorems with the help of Condition $\left(B^{\prime}\right)$.

Theorem 2.5. Let E be a real uniformly convex Banach space and $C$ a nonempty closed convex subset of $E$. Let $T_{i}: C \rightarrow C$ be a uniformly $L_{t, i}$-Lipschitz and generalized asymptotically quasi-nonexpansive mapping with sequences $\left\{k_{n, t, i}\right\} \subset[1, \infty)$ and $\left\{\xi_{n, t, i}\right\} \subset[0, \infty)$ such that $\sum_{n=1}^{\infty}\left(k_{n, t, i}-1\right)<\infty$ and $\sum_{n=1}^{\infty} \xi_{n, t, i}<\infty$ for each $1 \leq i \leq N$, and let $S_{i}: C \rightarrow C$ be a uniformly $L_{s, i}$-Lipschitz and generalized asymptotically quasi-nonexpansive mapping with sequences $\left\{k_{n, s, i}\right\} \subset[1, \infty)$ and $\left\{\xi_{n, s, i}\right\} \subset[0, \infty)$ such that $\sum_{n=1}^{\infty}\left(k_{n, s, i}-1\right)<\infty$ and $\sum_{n=1}^{\infty} \xi_{n, s, i}<\infty$ for each $1 \leq i \leq N$. Assume that $F=\cap_{i=1}^{N} F\left(T_{i}\right) \cap \cap_{i=1}^{N} F\left(S_{i}\right)$ is nonempty. Let $\left\{u_{n}\right\}$ be a bounded sequence in $C, k_{n}=\max \left\{k_{n, t}, k_{n, s}\right\}$, where $k_{n, t}=\max \left\{k_{n, t, i}: 1 \leq i \leq N\right\}$ and $k_{n, s}=\max \left\{k_{n, s, i}: 1 \leq i \leq N\right\}$ and $\xi_{n}=\max \left\{\xi_{n, t}, \xi_{n, s}\right\}$, where $\xi_{n, t}=\max \left\{\xi_{n, t, i}: 1 \leq i \leq N\right\}$ and $\xi_{n, s}=\max \left\{\xi_{n, s, i}: 1 \leq i \leq N\right\}$. Let $\left\{\alpha_{n}\right\},\left\{\beta_{n}\right\},\left\{\gamma_{n}\right\}$, and $\left\{\delta_{n}\right\}$ be sequences in $(0,1)$ such that $\alpha_{n}+\beta_{n}+\gamma_{n}+\delta_{n}=1$ for each $n \geq 1$. Let $\left\{x_{n}\right\}$ be a sequence generated in (1.18). Assume that the following restrictions are satisfied:

(a) there exist constants $a, b, c, d \in(0,1)$ such that $a \leq \alpha_{n}, b \leq \beta_{n}$, and $c \leq \gamma_{n} \leq d<1 / L_{t}$, where $L_{t}=\max \left\{L_{t, i}: 1 \leq i \leq N\right\}$, for all $n \geq 1$;

(b) $\sum_{n=1}^{\infty} \delta_{n}<\infty$.

If $\left\{S_{1}, S_{2}, \ldots, S_{N}\right\}$ and $\left\{T_{1}, T_{2}, \ldots, T_{N}\right\}$ satisfy Condition $\left(B^{\prime}\right)$, then the sequence converges strongly to some point in $F$.

Proof. In view of Condition $\left(B^{\prime}\right)$, we obtain from (2.27) and (2.38) that $f\left(d\left(x_{n}, F\right)\right) \rightarrow 0$, which implies $d\left(x_{n}, F\right) \rightarrow 0$. Next, we show that the sequence $\left\{x_{n}\right\}$ is Cauchy. In view of (2.6), for any positive integers $m, n$, where $m>n>n_{0}$, we see that

$$
\left\|x_{m}-p\right\| \leq B\left\|x_{n}-p\right\|+B \sum_{i=n+1}^{\infty} M_{1}\left(\delta_{i}+\xi_{h(i)}\right)+M_{1}\left(\delta_{m}+\xi_{h(m)}\right),
$$

where $B=\exp \left\{\sum_{n=1}^{\infty}\left(k_{h(n)}-1\right) /(1-R)\right\}$. It follows that

$$
\begin{aligned}
\left\|x_{n}-x_{m}\right\| & \leq\left\|x_{n}-p\right\|+\left\|x_{m}-p\right\| \\
& \leq(1+B)\left\|x_{n}-p\right\|+B \sum_{i=n+1}^{\infty} M_{1}\left(\delta_{i}+\xi_{h(i)}\right)+M_{1}\left(\delta_{m}+\xi_{h(m)}\right) .
\end{aligned}
$$

It follows that $\left\{x_{n}\right\}$ is a Cauchy sequence in $C$ and so $\left\{x_{n}\right\}$ converges strongly to some $\bar{q} \in C$. Since $T_{r}$ and $S_{r}$ are Lipschitz for each $r \in\{1,2, \ldots, N\}$, we see that $F$ is closed. This in turn implies that $\bar{q} \in F$. This completes the proof.

If $S_{i}=I$, where $I$ denotes the identity mapping, for each $i \in\{1,2, \ldots, N\}$, then Theorem 2.2 is reduced to the following.

Corollary 2.6. Let $E$ be a real uniformly convex uniformly convex Banach space and $C$ a nonempty closed convex subset of $E$. Let $T_{i}: C \rightarrow C$ be a uniformly $L_{t, i}$-Lipschitz and generalized asymptotically quasi-nonexpansive mapping with sequences $\left\{k_{n, t, i}\right\} \subset[1, \infty)$ and $\left\{\xi_{n, t, i}\right\} \subset[0, \infty)$ such that $\sum_{n=1}^{\infty}\left(k_{n, t, i}-1\right)<\infty$ and $\sum_{n=1}^{\infty} \xi_{n, t, i}<\infty$ for each $1 \leq i \leq N$. Assume that $F=\cap_{i=1}^{N} F\left(T_{i}\right)$ is nonempty. Let $\left\{u_{n}\right\}$ be a bounded sequence in $C, k_{n, t}=\max \left\{k_{n, t, i}: 1 \leq i \leq N\right\}$ and where $\xi_{n, t}=\max \left\{\xi_{n, t, i}: 1 \leq i \leq N\right\}$. Let $\left\{\alpha_{n}\right\},\left\{\beta_{n}\right\},\left\{\gamma_{n}\right\}$, and $\left\{\delta_{n}\right\}$ be sequences in $(0,1)$ such that 
$\alpha_{n}+\beta_{n}+\gamma_{n}+\delta_{n}=1$ for each $n \geq 1$. Let $\left\{x_{n}\right\}$ be a sequence generated in (1.19). Assume that the following restrictions are satisfied:

(a) there exist constants $a, b, c \in(0,1)$ such that $a \leq \alpha_{n}+\beta_{n}$ and $b \leq \gamma_{n} \leq c<1 / L_{t}$, where $L_{t}=\max \left\{L_{t, i}: 1 \leq i \leq N\right\}$, for all $n \geq 1$;

(b) $\sum_{n=1}^{\infty} \delta_{n}<\infty$.

If $\left\{T_{1}, T_{2}, \ldots, T_{N}\right\}$ satisfies Condition $(B)$, then the sequence $\left\{x_{n}\right\}$ converges strongly to some point in $F$.

If $T_{i}=I$, where $I$ denotes the identity mapping, for each $i \in\{1,2, \ldots, N\}$, then Theorem 2.2 is reduced to the following.

Corollary 2.7. Let $E$ be a real uniformly convex Banach space and $C$ a nonempty closed convex subset of $E$. Let $S_{i}: C \rightarrow$ C be a uniformly $L_{s, i}$-Lipschitz and generalized asymptotically quasi-nonexpansive mapping with sequences $\left\{k_{n, s, i}\right\} \subset[1, \infty)$ and $\left\{\xi_{n, s, i}\right\} \subset[0, \infty)$ such that $\sum_{n=1}^{\infty}\left(k_{n, s, i}-1\right)<\infty$ and $\sum_{n=1}^{\infty} \xi_{n, s, i}<\infty$ for each $1 \leq i \leq N$. Assume that $F=\cap_{i=1}^{N} F\left(S_{i}\right)$ is nonempty. Let $\left\{u_{n}\right\}$ be a bounded sequence in $C, k_{n, s}=\max \left\{k_{n, s, i}: 1 \leq i \leq N\right\}$, and $\xi_{n, s}=\max \left\{\xi_{n, s, i}: 1 \leq i \leq N\right\}$. Let $\left\{\alpha_{n}\right\},\left\{\beta_{n}\right\}$, $\left\{\gamma_{n}\right\}$, and $\left\{\delta_{n}\right\}$ be sequences in $(0,1)$ such that $\alpha_{n}+\beta_{n}+\gamma_{n}+\delta_{n}=1$ for each $n \geq 1$. Let $\left\{x_{n}\right\}$ be a sequence generated in (1.20). Assume that the following restrictions are satisfied:

(a) there exist constants $a, b, c, d \in(0,1)$ such that $a \leq \alpha_{n}, b \leq \beta_{n}$ and $c \leq \gamma_{n}$, for all $n \geq 1$;

(b) $\sum_{n=1}^{\infty} \delta_{n}<\infty$.

If $\left\{S_{1}, S_{2}, \ldots, S_{N}\right\}$ satisfies Condition $(B)$, then the sequence $\left\{x_{n}\right\}$ converges strongly to some point in $F$.

Finally, we give a strong convergence theorem criterion.

Theorem 2.8. Let $E$ be a real Banach space and $C$ a nonempty closed convex subset of $E$. Let $T_{i}: C \rightarrow C$ be a uniformly $L_{t, i}$-Lipschitz and generalized asymptotically quasi-nonexpansive mapping with sequences $\left\{k_{n, t, i}\right\} \subset[1, \infty)$ and $\left\{\xi_{n, t, i}\right\} \subset[0, \infty)$ such that $\sum_{n=1}^{\infty}\left(k_{n, t, i}-1\right)<\infty$ and $\sum_{n=1}^{\infty} \xi_{n, t, i}<\infty$ for each $1 \leq i \leq N$, and let $S_{i}: C \rightarrow C$ be a uniformly $L_{s, i}-$ Lipschitz and generalized asymptotically quasi-nonexpansive mapping with sequences $\left\{k_{n, s, i}\right\} \subset[1, \infty)$ and $\left\{\xi_{n, s, i}\right\} \subset[0, \infty)$ such that $\sum_{n=1}^{\infty}\left(k_{n, s, i}-1\right)<\infty$ and $\sum_{n=1}^{\infty} \xi_{n, s, i}<\infty$ for each $1 \leq i \leq N$. Assume that $F=\cap_{i=1}^{N} F\left(T_{i}\right) \cap \cap_{i=1}^{N} F\left(S_{i}\right)$ is nonempty. Let $\left\{u_{n}\right\}$ be a bounded sequence in $C, k_{n}=\max \left\{k_{n, t}, k_{n, s}\right\}$, where $k_{n, t}=\max \left\{k_{n, t, i}: 1 \leq i \leq N\right\}$ and $k_{n, s}=\max \left\{k_{n, s, i}: 1 \leq i \leq N\right\}$ and $\xi_{n}=\max \left\{\xi_{n, t}, \xi_{n, s}\right\}$, where $\xi_{n, t}=\max \left\{\xi_{n, t, i}: 1 \leq i \leq N\right\}$ and $\xi_{n, s}=\max \left\{\xi_{n, s, i}: 1 \leq i \leq N\right\}$. Let $\left\{\alpha_{n}\right\},\left\{\beta_{n}\right\},\left\{\gamma_{n}\right\}$, and $\left\{\delta_{n}\right\}$ be sequences in $(0,1)$ such that $\alpha_{n}+\beta_{n}+\gamma_{n}+\delta_{n}=1$ for each $n \geq 1$. Let $\left\{x_{n}\right\}$ be a sequence generated in (1.18). Assume that the following restrictions are satisfied:

(a) there exist constants $a, b, c, d \in(0,1)$ such that $a \leq \alpha_{n}, b \leq \beta_{n}$, and $c \leq \gamma_{n} \leq d<1 / L_{t}$, where $L_{t}=\max \left\{L_{t, i}: 1 \leq i \leq N\right\}$, for all $n \geq 1$;

(b) $\sum_{n=1}^{\infty} \delta_{n}<\infty$.

Then $\left\{x_{n}\right\}$ converges strongly to some point in $F$ if and only if $\liminf _{n \rightarrow \infty} d\left(x_{n}, F\right)=0$.

Proof. The necessity is obvious. We only show the sufficiency. Assume that

$$
\liminf _{n \rightarrow \infty} d\left(x_{n}, \mp\right)=0
$$


For each $p \in F$, we see that

$$
\begin{aligned}
\left\|x_{n}-p\right\| \leq & \alpha_{n}\left\|x_{n-1}-p\right\|+\beta_{n}\left\|S_{i(n)}^{h(n)} x_{n-1}-p\right\|+\gamma_{n}\left\|T_{i(n)}^{h(n)} x_{n}-p\right\|+\delta_{n}\left\|u_{n}-p\right\| \\
\leq & \alpha_{n}\left\|x_{n-1}-p\right\|+\beta_{n}\left(k_{h(n)}\left\|x_{n-1}-p\right\|+\xi_{h(n)}\right)+\gamma_{n}\left(k_{h(n)}\left\|x_{n}-p\right\|+\xi_{h(n)}\right) \\
& +\delta_{n}\left\|u_{n}-p\right\| \\
\leq & \left(\alpha_{n}+\beta_{n} k_{h(n)}\right)\left\|x_{n-1}-p\right\|+\left(1-\alpha_{n}-\beta_{n}\right) k_{h(n)}\left\|x_{n}-p\right\|+2 \xi_{h(n)} \\
& +\delta_{n}\left\|u_{n}-x_{n}\right\| .
\end{aligned}
$$

Notice that $\sum_{n=1}^{\infty}\left(k_{n}-1\right)<\infty$. We see from the restrictions (a) and (b) that there exists a positive integer $n_{0}$ such that

$$
\left(1-\alpha_{n}-\beta_{n}\right) k_{h(n)} \leq R<1, \quad \forall n \geq n_{0}
$$

where $R=(1-(a+b))(1+(a+b) /(2-2(a+b)))$. Notice that the sequence $\left\{x_{n}\right\}$ is bounded. It follows from (2.46) that

$$
\begin{aligned}
\left\|x_{n}-p\right\| \leq & \frac{\alpha_{n}+\beta_{n} k_{h(n)}}{1-\left(1-\alpha_{n}-\beta_{n}\right) k_{h(n)}}\left\|x_{n-1}-p\right\|+\frac{\delta_{n}}{1-\left(1-\alpha_{n}-\beta_{n}\right) k_{h(n)}}\left\|u_{n}-x_{n}\right\| \\
& +\frac{2 \xi_{h(n)}}{1-\left(1-\alpha_{n}-\beta_{n}\right) k_{h(n)}} \\
\leq & \left(1+\frac{k_{h(n)}-1}{1-R}\right)\left\|x_{n-1}-p\right\|+\frac{\delta_{n}}{1-R}\left\|u_{n}-x_{n}\right\|+\frac{2 \xi_{h(n)}}{1-R} \\
\leq & \left(1+\frac{k_{h(n)}-1}{1-R}\right)\left\|x_{n-1}-p\right\|+M_{4}\left(\delta_{n}+\xi_{h(n)}\right), \quad \forall n \geq n_{0}
\end{aligned}
$$

where $M_{4}$ is an appropriate constant such that $M_{4}=\max \left\{\sup _{n>1}\left\{\left\|u_{n}-x_{n}\right\| /(1-R)\right\}, 2 /(1-\right.$ $R)\}$. In view of the restrictions (a) and (b), we obtain from Lemma 1.2 that $\lim _{n \rightarrow \infty} d\left(x_{n}, \mathcal{F}\right)$ exists. This implies that

$$
\lim _{n \rightarrow \infty} d\left(x_{n}, \mathcal{F}\right)=0
$$

In view of Theorem 2.5, we can conclude the desired conclusion easily.

If $S_{i}=I$, where $I$ denotes the identity mapping, for each $i \in\{1,2, \ldots, N\}$, then Theorem 2.2 is reduced to the following.

Corollary 2.9. Let $E$ be a real Banach space and $C$ a nonempty closed convex subset of $E$. Let $T_{i}$ : $C \rightarrow C$ be a uniformly $L_{t, i}-$ Lipschitz and generalized asymptotically quasi-nonexpansive mapping with sequences $\left\{k_{n, t, i}\right\} \subset[1, \infty)$ and $\left\{\xi_{n, t, i}\right\} \subset[0, \infty)$ such that $\sum_{n=1}^{\infty}\left(k_{n, t, i}-1\right)<\infty$ and $\sum_{n=1}^{\infty} \xi_{n, t, i}<$ $\infty$ for each $1 \leq i \leq N$. Assume that $F=\cap_{i=1}^{N} F\left(T_{i}\right)$ is nonempty. Let $\left\{u_{n}\right\}$ be a bounded sequence in $C, k_{n, t}=\max \left\{k_{n, t, i}: 1 \leq i \leq N\right\}$ and where $\xi_{n, t}=\max \left\{\xi_{n, t, i}: 1 \leq i \leq N\right\}$. Let $\left\{\alpha_{n}\right\},\left\{\beta_{n}\right\},\left\{\gamma_{n}\right\}$ 
and $\left\{\delta_{n}\right\}$ be sequences in $(0,1)$ such that $\alpha_{n}+\beta_{n}+\gamma_{n}+\delta_{n}=1$ for each $n \geq 1$. Let $\left\{x_{n}\right\}$ be a sequence generated in (1.19). Assume that the following restrictions are satisfied:

(a) there exist constants $a, b, c \in(0,1)$ such that $a \leq \alpha_{n}+\beta_{n}$ and $b \leq \gamma_{n} \leq c<1 / L_{t}$, where $L_{t}=\max \left\{L_{t, i}: 1 \leq i \leq N\right\}$, for all $n \geq 1$;

(b) $\sum_{n=1}^{\infty} \delta_{n}<\infty$.

Then $\left\{x_{n}\right\}$ converges strongly to some point in $F$ if and only if $\lim _{\operatorname{minf}} \rightarrow \infty d\left(x_{n}, F\right)=0$.

If $T_{i}=I$, where $I$ denotes the identity mapping, for each $i \in\{1,2, \ldots, N\}$, then Theorem 2.2 is reduced to the following.

Corollary 2.10. Let $E$ be a real Banach space and $C$ a nonempty closed convex subset of $E$. Let $S_{i}$ : $C \rightarrow C$ be a uniformly $L_{s, i}$-Lipschitz and generalized asymptotically quasi-nonexpansive mapping with sequences $\left\{k_{n, s, i}\right\} \subset[1, \infty)$ and $\left\{\xi_{n, s, i}\right\} \subset[0, \infty)$ such that $\sum_{n=1}^{\infty}\left(k_{n, s, i}-1\right)<\infty$ and $\sum_{n=1}^{\infty} \xi_{n, s, i}<$ $\infty$ for each $1 \leq i \leq N$. Assume that $F=\cap_{i=1}^{N} F\left(S_{i}\right)$ is nonempty. Let $\left\{u_{n}\right\}$ be a bounded sequence in $C$, $k_{n, s}=\max \left\{k_{n, s, i}: 1 \leq i \leq N\right\}$, and $\xi_{n, s}=\max \left\{\xi_{n, s, i}: 1 \leq i \leq N\right\}$. Let $\left\{\alpha_{n}\right\},\left\{\beta_{n}\right\},\left\{\gamma_{n}\right\}$, and $\left\{\delta_{n}\right\}$ be sequences in $(0,1)$ such that $\alpha_{n}+\beta_{n}+\gamma_{n}+\delta_{n}=1$ for each $n \geq 1$. Let $\left\{x_{n}\right\}$ be a sequence generated in (1.20). Assume that the following restrictions are satisfied:

(a) there exist constants $a, b, c, d \in(0,1)$ such that $a \leq \alpha_{n}, b \leq \beta_{n}$, and $c \leq \gamma_{n}$, for all $n \geq 1$;

(b) $\sum_{n=1}^{\infty} \delta_{n}<\infty$.

Then $\left\{x_{n}\right\}$ converges strongly to some point in $F$ if and only if $\liminf _{n \rightarrow \infty} d\left(x_{n}, F\right)=0$.

\section{References}

[1] W. G. Dotson, Jr., "Fixed points of quasi-nonexpansive mappings," Australian Mathematical Society A, vol. 13, pp. 167-170, 1972.

[2] K. Goebel and W. A. Kirk, "A fixed point theorem for asymptotically nonexpansive mappings," Proceedings of the American Mathematical Society, vol. 35, pp. 171-174, 1972.

[3] W. A. Kirk, "Fixed point theorems for non-Lipschitzian mappings of asymptotically nonexpansive type," Israel Journal of Mathematics, vol. 17, pp. 339-346, 1974.

[4] R. Bruck, T. Kuczumow, and S. Reich, "Convergence of iterates of asymptotically nonexpansive mappings in Banach spaces with the uniform Opial property," Colloquium Mathematicum, vol. 65, no. 2, pp. 169-179, 1993.

[5] H. K. Xu, "Existence and convergence for fixed points of mappings of asymptotically nonexpansive type," Nonlinear Analysis: Theory, Methods E Applications, vol. 16, no. 12, pp. 1139-1146, 1991.

[6] N. Shahzad and H. Zegeye, "Strong convergence of an implicit iteration process for a finite family of generalized asymptotically quasi-nonexpansive maps," Applied Mathematics and Computation, vol. 189, no. 2, pp. 1058-1065, 2007.

[7] S. Saejung, S. Suantai, and P. Yotkaew, "a note on common fixed point of multistep Noor iteration with errors for a finite family of generalized asymptotically quasi-nonexpansive mapping," Abstract and Applied Analysis, vol. 2009, Article ID 283461, 9 pages, 2009.

[8] J. Schu, "Weak and strong convergence to fixed points of asymptotically nonexpansive mappings," Bulletin of the Australian Mathematical Society, vol. 43, no. 1, pp. 153-159, 1991.

[9] Z. Sun, "Strong convergence of an implicit iteration process for a finite family of asymptotically quasinonexpansive mappings," Journal of Mathematical Analysis and Applications, vol. 286, no. 1, pp. 351-358, 2003.

[10] S. S. Chang, K. K. Tan, H. W. J. Lee, and C. K. Chan, “On the convergence of implicit iteration process with error for a finite family of asymptotically nonexpansive mappings," Journal of Mathematical Analysis and Applications, vol. 313, no. 1, pp. 273-283, 2006.

[11] C. E. Chidume and N. Shahzad, "Strong convergence of an implicit iteration process for a finite family of nonexpansive mappings," Nonlinear Analysis: Theory, Methods E Applications, vol. 62, no. 6, pp. 1149-1156, 2005. 
[12] W. Guo and Y. J. Cho, "On the strong convergence of the implicit iterative processes with errors for a finite family of asymptotically nonexpansive mappings," Applied Mathematics Letters, vol. 21, no. 10, pp. 1046-1052, 2008.

[13] J. K. Kim, Y. M. Nam, and J. Y. Sim, "Convergence theorems of implicit iterative sequences for a finite family of asymptotically quasi-nonxpansive type mappings," Nonlinear Analysis: Theory, Methods $\mathcal{E}$ Applications, vol. 71, no. 12, pp. e2839-e2848, 2009.

[14] X. Qin, Y. J. Cho, and M. Shang, "Convergence analysis of implicit iterative algorithms for asymptotically nonexpansive mappings," Applied Mathematics and Computation, vol. 210, no. 2, pp. 542-550, 2009.

[15] S. Thianwan and S. Suantai, "Weak and strong convergence of an implicit iteration process for a finite family of nonexpansive mappings," Scientiae Mathematicae Japonicae, vol. 66, no. 1, pp. 73-81, 2007.

[16] H.-K. Xu and R. G. Ori, "An implicit iteration process for nonexpansive mappings," Numerical Functional Analysis and Optimization, vol. 22, no. 5-6, pp. 767-773, 2001

[17] Y. Zhou and S.-S. Chang, "Convergence of implicit iteration process for a finite family of asymptotically nonexpansive mappings in Banach spaces," Numerical Functional Analysis and Optimization, vol. 23, no. 7-8, pp. 911-921, 2002.

[18] K.-K. Tan and H. K. Xu, "Approximating fixed points of nonexpansive mappings by the Ishikawa iteration process," Journal of Mathematical Analysis and Applications, vol. 178, no. 2, pp. 301-308, 1993.

[19] Y. Hao, S. Y. Cho, and X. Qin, "Some weak convergence theorems for a family of asymptotically nonexpansive nonself mappings," Fixed Point Theory and Applications, Article ID 218573, 11 pages, 2010. 